\title{
INVESTIGATION OF THE MECHANICAL BEHAVIOR OF RING SECTIONED TRANSMISSION STEELS COMBINED WITH DIFFERENT ADHESIVES
}

\author{
Anıl İmak ${ }^{* 1}$, Aydın Turgut ${ }^{1}$ \\ ${ }^{1}$ Bingol University, Faculty of Engineering and Architecture, Department of Mechanical Engineering, Turkey
}

\begin{abstract}
Original scientific paper

The aim of this study is to investigate the effect of the environmental adhesion surface on the bond strength of the ring-sectioned transmission steel bars on the butt. Male and female molds were produced in order to make the joints of the shafts. With two different adhesives (DP 410, DP 490), four different overlap distances $(10 \mathrm{~mm}, 20 \mathrm{~mm}, 30 \mathrm{~mm}, 40 \mathrm{~mm})$ and two different overlap angles $\left(30^{\circ}, 90^{\circ}\right)$ rods are combined with the adhesive. Mechanical behavior of peripheral bonding surface of which is adhered with an overlap butt sample was assayed according to the determined parameters. Tensile and torsion experiments of ring cross-section rods combined with adhesive were performed. The graphs of the experimental data obtained were prepared and compared. DP 410 affixed with adhesive ring sectioned rod showed the better performance of the rods, prepared by the DP 490 adhesive.
\end{abstract}

\section{FARKLI YAPIŞTIRICILARLA BIRLEŞTIRIILEN HALKA KESITLI TRANSMISYON ÇELIKLERININ MEKANIK DAVRANIŞLARININ ARAŞTIRILMASI}

$\ddot{O}_{z e t}$

Orijinal Bilimsel Makale

Bu çalıșmanın amacı halka kesitli transmisyon çeliği çubukların alın alına bindirmeli olarak yapıștırılmasında cevresel yapıșma yüzeyinin bağlantı mukavemetine etkisinin araştırılması amaçlanmıştır. Millerin alın alına birleştirmelerinin yapılabilmesi için erkek ve dişi kalıp olarak üretimleri yapılmıştır. İki faklı (DP410, DP490) yapıştırıcı ile dört farklı bindirme mesafesi $(10 \mathrm{~mm}, 20 \mathrm{~mm}, 30 \mathrm{~mm}, 40 \mathrm{~mm})$ ve iki farklı bindirme açı1 $\left(30^{\circ}, 90^{\circ}\right)$ çubuklar yapış̧ırıcı ile birleștirilmiştir. Belirlenen parametreler doğrultusunda alın alına bindirmeli olarak yapıştırılan numunelerin çevresel yapışma yüzeylerinin mekanik davranışları incelenmiştir. Yapıştırıcıyla birleştirilmiş halka kesitli çubukların çekme ve burulma deneyleri yapılmıştır. Elde edilen deneysel verilerin grafikleri hazırlanmıș ve değerlendirilerek kıyaslanmıștır. DP410 yapıștırıcıyla yapıștııılmış halka kesitli çubuklar DP 490 yapıștırıcıyla hazırlanmıș olan çubuklara göre daha iyi performans göstermiştir.

Anahtar kelimeler: Burulma, gerilme analizi, Halka kesitli çubuk, Yapıştırıcı

\section{Giriş}

Otomotiv endüstrisinde kullanılan güç iletim sistemlerinin en önemli elemanlarından biri olan miller (şaft), çalışma yapısı bakımından genellikle eğilme ve burulmaya maruz kalmaktadırlar. Günümüz endüstrisinde kompozit, plastik ve metal malzemelerin birleştirmelerinde kaynak, perçin lehim ve yapıştırıcı ile bağlantı yöntemleri kullanılmaktadır. Yapıştırıcı ile bağlantı oluşturma, yaygın bir kullanım alanı olan ve gün geçtikçe hızlı bir şekilde kullanımında artış gösterilen bir yöntemdir [1-2]. Yapıştırma yöntemi kullanılarak yapılan birleştirmenin, kaynak yöntemine göre yüksek sıcaklık ve lehimlemede gerekli olan metal malzeme ihtiyacinı ortadan kaldırmaktadır [3]. Kaynak ile birleştirme yönteminde perçinlemedeki malzemenin birleştirme elemanı olan perçin birleştirme bölgesinden uzaklaştırması, korozyon ve kalıntı 1sıl gerilimlerin oluşmasına sebep olmaktadır. Bu oluşum metal-metal birleşimlerinde ön yükleme gibi bağlantı dayanımlarını düşüren dezavantajlar oluşturmaktadır. Ayrıca geleneksel yöntemler ile birleştirmede ortamdaki nemden veya sıvı ile temasında metal-metal birleşimlerin teması kesilmediğinden dolayı korozyon artarak birleştirmenin dayanım süresini azaltmaktadır. Özellikle sulu ortamlardaki yoğun olarak basınçlı akışkan taşındığı düşünülen metal boruların kaynak yöntemi kullanılarak birleştirilmesinde zamanla korozyona sebep olmaktadır. Mikro boyuttaki bir çatlağın dahi basınçlı bir akışkan taşıyan bu boruda büyük hasar boyutları oluşturabilmektedir [4-5].

Metal-metal birleştirme bölgelerindeki iyileştirmelerde hassasiyetlere karşılık verebildiği için yapıştırıcı yöntemi, endüstriyel bir birleştirme yöntemi olarak tercih edilmeye başlamıştır. Yaygınlaşan yapıştırıcı kullanımı ile birlikte birleştirmede en önemli parametrelerin elde edilmesi içinde literatürde birçok araştırma ve geliştirme çalışmaları yapılmaktadır [6-9]. 
Jeroen ve ark., yaptıkları çalışmada standart API hat borusu kuplajının yorulma davranışını deneysel olarak incelemişlerdir [10]. Kaplin geometrisinin yorulma ömrüne etkisini, 4 nokta eğilme yorulma testiyle incelemişlerdir. Elde ettikleri verileri deneysel ve sayısal olarak değerlendirmişlerdir. Vaziri ve ark., çalışmalarında harmonik bir eksenel yüke maruz kalan yapışkan olarak bağlanmış tübüler eklemlerin dinamik tepkilerini belirlemişlerdir [11]. Borulu eklem geometrilerinin, malzeme özelliklerinin ve yapışkan özelliklerinin sistemin dinamik tepkisi üzerine etkilerini incelemişlerdir. Das ve ark., yaptıkları çalışmada iç basınca maruz tabakalı FRP kompozit borular ile yapıştırılmış soket bağlantılarının üç boyutlu gerilme analizini yapmışlardır [12]. Li ve ark. çalışmalarında korozyon önleyici plastik alaşımlı kompozit boruya yapıştırılmış yapışkan metal parçasının gerilme analizini incelemişlerdir [13]. Rohem ve ark. Bu çalışmada borularda tamir için yeni bir polimerik matris kompozitin incelemesini yapmışlardır. İlk önce, mekanik ve termal olmak üzere yeni geliştirilen kompozit tabakanın özelliklerini belirlemişler ve borunun performansının değerlendirilmesini hidrostatik testlerle yapmışlardır [14]. Liu ve ark., çalışmalarında CFRP yamaları ile tamir edilmiş çatlağı olan alüminyum alaşımlı boru performanslarını tam olarak anlamak için 7005 tipi ticari borularda bir dizi yorulma ve yarı-statik testler yapmışlardır. Yapay çatlaklar ile hasar görmüş olan boru şekillendirilmiş CFRP yamaları ile sarılmıştır. Onarım işleminde vida dişi ve mekanik taşlama yöntemleri uygulanmıştır. Yama uzunluğunun ve katman sayısının etkileri aynı zamanda değerlendirilmiştir. Optimize olarak tasarlanmış CFRP yaması onarılmış alüminyum boruların yorulma testlerinde en iyi sonuçları vermiştir[15].

Yapılan literatür [1-15] incelemelerinde halka kesitli parçaların yapıştırıcı ile birleştirilmeleri neredeyse hiç çalışılmadığı görülmüştür. Bu sebeple bu çalışmada farklı özelliklere sahip iki tür yapıştırıcı ile birbirine geçmeli olarak birleştirilen halka kesitli transmisyon millerinin mekanik ve burulma davranışları araştırılmıştır.

\section{Material ve yöntem}

Deney çalışmalarında, Max. \%0.2 C, \%0.007 N, $\% 0.05 \mathrm{P}$ ve $\% 0.05 \mathrm{~S}$ kimyasal kompozisyona sahip ve akma dayanımı $235 \mathrm{MPa}$, çekme dayanımı ise 360-460 $\mathrm{MPa}$ arasında olan St37 standartlarında, $30 \mathrm{~mm}$ çapında transmisyon çeliği ve DP410 ile DP490 yapıştırıcılar kullanıldı. Yapıştırıcılara ait özellikler ise Tablo 1 de verilmiştir. Birleştirme öncesi çubuklar torna tezgâhında Şekil 1' de verildiği gibi birbiri içine geçmeli olacak şekilde hazırlandı. Birleştirme işlemleri, Şekil 2' de gösterildiği gibi ve Tablo 2' de ki parametreler kullanılarak yapılmıştır. Standartlara uygun olarak hazırlanan DP 410 ve DP 490 bulk numuneleri ve yapıştırıcı ile birleştirilmiş numunelerin çekme deneyleri Batman Üniversitesi, Mühendislik Mimarlık Fakültesi Makine Mühendisliği Bölümü Laboratuvarı'nda bulunan SHMADZU marka ve $250000 \mathrm{~N}$ kapasiteye sahip çekme test cihazında yapılmıştır. Birbiri içine geçmeli olarak üretilen numuneler daha sonra DP410 ve DP490 yapıştırıcılarıyla birleştirilip burulma analizleri de yapılmıştır. $\mathrm{Bu}$ analizler Atatürk Üniversitesi Mühendislik Fakültesi Makine Mühendisliği Bölümü Laboratuvarı'nda JiNAN NDW-200 marka ve maksimum çalışma torku 170 N.m olan burulma cihazında gerçekleştirilmiştir

Tablo 1. DP 410 ve DP 490 yapıştırıcılarının özellikleri.

\begin{tabular}{lcc}
\hline & DP410 & DP490 \\
\hline \hline Yapışkanın cinsi & Epoksi & Epoksi \\
\cline { 1 - 1 } Renk & Kirli Beyaz & Siyah \\
\cline { 1 - 1 } Viskozite & Tiksotroptik & Tiksotroptik \\
\cline { 1 - 1 } Soyma Dayanımı ( Al, N/cm ) & 100 & 92 \\
\cline { 1 - 1 } Kayma Dayanımı (Al - MPa ) & 34 & 30.2 \\
\cline { 1 - 1 } Kürleşme Zamanı ( dk ) & $25-30$ & $200-240$ \\
\cline { 1 - 1 } Kuruma Zamanı ( dk ) & $8-10$ & 180 \\
\hline \hline
\end{tabular}

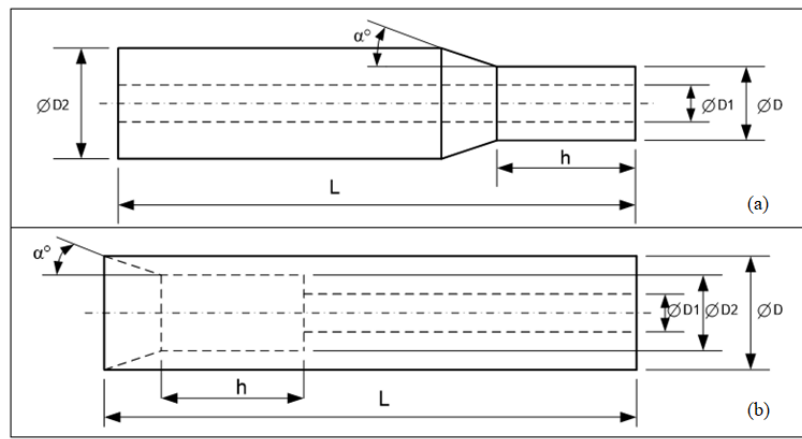

Şekil 1. Halka kesitli çubuk numunelerin parametreleri (a) erkek numune, (b) dişi numune

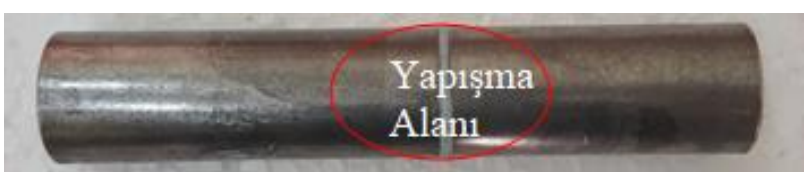

Şekil 2. Yapıştırıcıyla birleştirilmiş numune

Tablo 2. Çalışmada kullanılan numunelerin parametreleri

\begin{tabular}{|c|c|c|c|c|c|c|}
\hline $\begin{array}{l}\text { Numune } \\
\text { No: }\end{array}$ & $D(\mathrm{~mm})$ & $\mathrm{D} 1(\mathrm{~mm})$ & D2 (mm) & $\mathrm{L}(\mathrm{mm})$ & $h(\mathrm{~mm})$ & $a^{\circ}$ (derece \\
\hline 1 & 30 & 10 & 15 & 100 & 10 & 30 \\
\hline 2 & 30 & 10 & 20 & 100 & 10 & 30 \\
\hline 3 & 30 & 10 & 15 & 100 & 20 & 30 \\
\hline 4 & 30 & 10 & 20 & 100 & 20 & 30 \\
\hline 5 & 30 & 10 & 15 & 100 & 30 & 30 \\
\hline 6 & 30 & 10 & 20 & 100 & 30 & 30 \\
\hline 7 & 30 & 10 & 15 & 100 & 40 & 30 \\
\hline 8 & 30 & 10 & 20 & 100 & 40 & 30 \\
\hline 9 & 30 & 10 & 15 & 100 & 10 & 90 \\
\hline 10 & 30 & 10 & 20 & 100 & 10 & 90 \\
\hline 11 & 30 & 10 & 15 & 100 & 20 & 90 \\
\hline 12 & 30 & 10 & 20 & 100 & 20 & 90 \\
\hline 13 & 30 & 10 & 15 & 100 & 30 & 90 \\
\hline 14 & 30 & 10 & 20 & 100 & 30 & 90 \\
\hline 15 & 30 & 10 & 15 & 100 & 40 & 90 \\
\hline 16 & 30 & 10 & 20 & 100 & 40 & 90 \\
\hline
\end{tabular}


Çalışmada kullanılan numunelerin çekme deneylerinde $\mathrm{S}$ harfi, burulma deneylerinde ise $\mathrm{T}$ harfi kullanılmıştır. Ayrıca DP410 ve DP490 yapıştırıcıları ise alt indis olarak belirtilmiştir. Örneğin, çekme deneyinde 1 nolu numunenin DP410 ile yapıştırılması durumunda $\mathrm{S}_{410}$ şeklinde, burulma için ise $\mathrm{T} 1_{410}$ olarak belirtilmiştir.

\section{Sonuçlar ve tartışma}

\subsection{DP410 ile Birleştirilen Numunelerde ' $h$ ' Bindirme Mesafesinin Çekme Kuvvetine Etkisinin İncelenmesi}

Yapıştırma işleminde DP410 kullanılan ve aynı bindirme çapı ile iç çapına sahip numunelerde ' $h$ ' değişiminin etkisine bakılmıştır. Dört farklı bindirme mesafesinin kıyaslanmasıyla oluşturulan grafikler Şekil 3, 4,5 ve 6 'da sırasıyla verilmiştir.

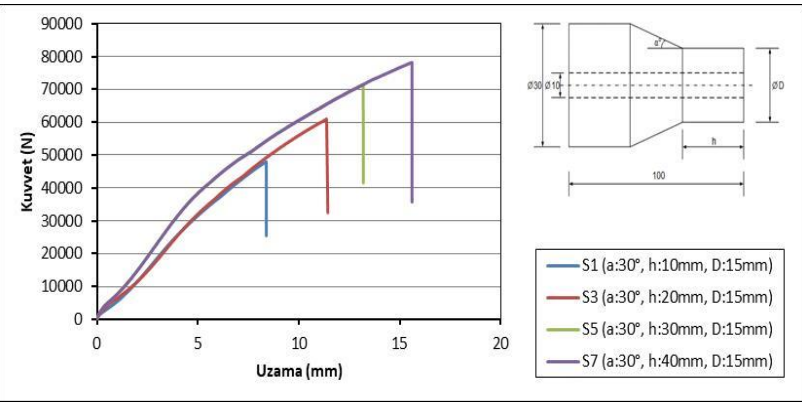

Şekil 3. DP410 yapıștırıcı kullanarak birleștirilen $\mathrm{S} 1_{410}\left(\mathrm{a}: 30^{\circ}, \mathrm{h}: 10 \mathrm{~mm}\right.$ D: $15 \mathrm{~mm}), S 3_{410}\left(\mathrm{a}: 30^{\circ}, \mathrm{h}: 20 \mathrm{~mm}, \mathrm{D}: 15 \mathrm{~mm}\right), \mathrm{S}_{410}\left(\mathrm{a}: 30^{\circ}, \mathrm{h}: 30 \mathrm{~mm}\right.$, $D: 15 \mathrm{~mm})$ ve $S 7_{410}\left(\mathrm{a}: 30^{\circ}, \mathrm{h}: 40 \mathrm{~mm}, \mathrm{D}: 15 \mathrm{~mm}\right)$ nolu numunelerde ' $h$ ' bindirme mesafesinin çekme kuvvetine etkisi

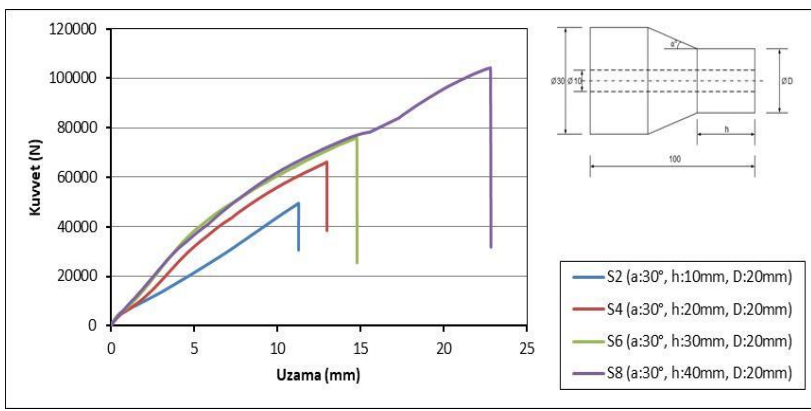

Şekil 4. DP410 yapıștırıcı kullanarak birleştirilen $\mathrm{S} 2_{410}$ (a:30 ${ }^{\circ}, \mathrm{h}: 10 \mathrm{~mm}$, D:20mm), S4 410 (a:30 $, \mathrm{h}: 20 \mathrm{~mm}, \mathrm{D}: 20 \mathrm{~mm}), \mathrm{S}_{410}\left(\mathrm{a}: 30^{\circ}, \mathrm{h}: 30 \mathrm{~mm}\right.$, D:20mm) ve $S 8_{410}\left(a: 30^{\circ}, h: 40 \mathrm{~mm}, \mathrm{D}: 20 \mathrm{~mm}\right)$ nolu numunelerde ' $h$ ' bindirme mesafesinin çekme kuvvetine etkisi

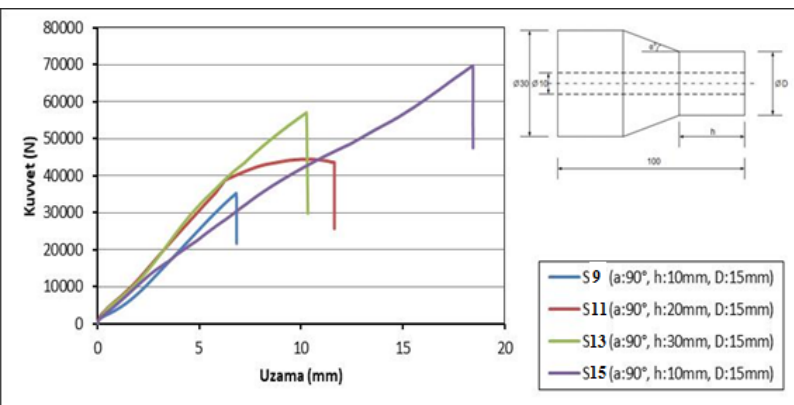

Sekil 5. DP 410 yapıștırıcı kullanarak birleștirilen $\mathrm{S} 9410$ (a:90 h:10mm, D:15mm), S1 $1_{410}\left(\mathrm{a}: 90^{\circ}, \mathrm{h}: 20 \mathrm{~mm}, \mathrm{D}: 15 \mathrm{~mm}\right), \mathrm{S} 13_{410}$ (a: $90^{\circ}$, $\mathrm{h}: 30 \mathrm{~mm}, \mathrm{D}: 15 \mathrm{~mm})$ ve $\mathrm{S} 15_{410}\left(\mathrm{a}: 90^{\circ}\right.$, h:40mm, D:15mm) nolu numunelerde ' $\mathrm{h}$ ' bindirme mesafesinin çekme kuvvetine etkisi

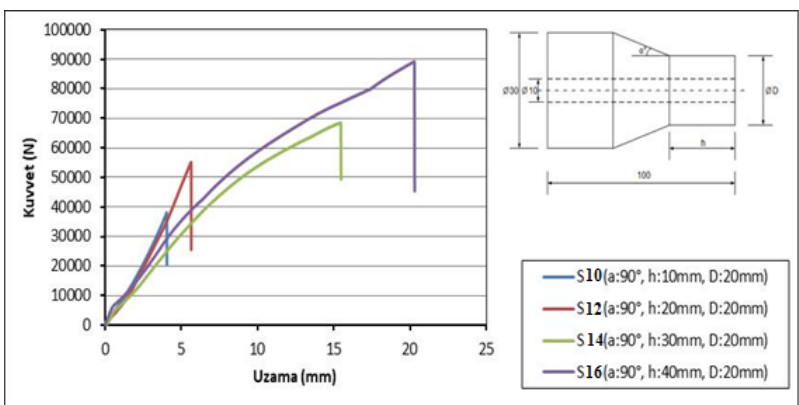

Şekil 6. DP410 yapıştırıcı kullanarak birleştirilen $\mathrm{S} 10_{410}\left(\mathrm{a}: 90^{\circ}\right.$, h:10mm, D:20mm), S12 ${ }_{410}\left(\mathrm{a}: 90^{\circ}, \mathrm{h}: 20 \mathrm{~mm}, \mathrm{D}: 20 \mathrm{~mm}\right), \mathrm{S} 14_{410}\left(\mathrm{a}: 90^{\circ}\right.$ h:30mm, D:20mm) ve S16 $6_{410}\left(\mathrm{a}: 90^{\circ}, \mathrm{h}: 40 \mathrm{~mm}, \mathrm{D}: 20 \mathrm{~mm}\right)$ nolu numunelerde ' $\mathrm{h}$ ' bindirme mesafesinin çekme kuvvetine etkisi

DP410 yapıştırıcısı kullanılarak dört farklı (10mm, $20 \mathrm{~mm}, 30 \mathrm{~mm}, 40 \mathrm{~mm}$ ) h bindirme mesafelerinde halka kesitli çubukların birleştirilmesi yapılmıştır. Yapılan birleștirmelerde $\mathrm{h}$ bindirme mesafesinin bağlantı mukavemetine etkisini incelemek için DP410 ile birleştirilmiş numuneler çekme yüküne maruz bırakılmıştır. Birleştirmelerin çekme kuvvetleri altındaki davranışları incelendiğinde genel olarak $\mathrm{h}$ bindirme mesafesi artıkça çekme yükünün arttığı görülmüştür. Çekme kuvvet değerleri incelendiği, maksimum ve minimum çekme kuvveti değerleri $\mathrm{S} 8_{410}$ ve $\mathrm{S} 9_{410}$ nolu numuneler de sirasiyla $104226.6 \mathrm{~N}$ ve $35328,13 \mathrm{~N}$ olarak elde edilmiștir. $\mathrm{Bu}$ durumun $\mathrm{h}$ bindirme mesafesinin artmasına paralel olarak yapışma yüzey alanın artmasına bağlı olduğu düşünülmektedir.

\subsection{DP490 ile Birleştirilen Numunelerde ' $h$ ' Bindirme Mesafesinin Çekme Kuvvetine Etkisinin İncelenmesi}

Yapıştırma işleminde DP490 kullanılan ve aynı bindirme çapı ile iç çapına sahip numunelerde ' $h$ ' değişimininin etkisine bakılmıştır. Dört farklı bindirme mesafesinin kıyaslanmasıyla oluşturulan Şekil 7, 8, 9 ve 10 'da sırasıyla verilmiştir.

DP490 yapıştırıcısı kullanılarak dört farklı $(10 \mathrm{~mm}$, $20 \mathrm{~mm}, 30 \mathrm{~mm}, 40 \mathrm{~mm}$ ) h bindirme mesafelerinde halka kesitli çubukların birleștirilmesi yapılmıştır. Yapılan birleştirmelerde $\mathrm{h}$ bindirme mesafesinin bağlantı mukavemetine etkisini incelemek için DP490 ile birleştirilmiş numuneler çekme yüküne maruz bırakılmıştır. Birleştirmelerin çekme kuvvetleri altındaki davranışları incelendiğinde genel olarak $h$ bindirme mesafesi artıkça çekme yükünün arttığı görülmüştür.

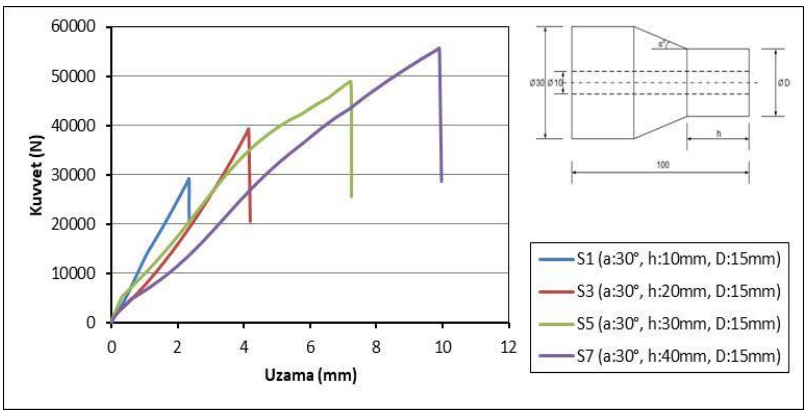

Şekil 7. DP 490 yapıștırıcı kullanarak birleștirilen $\mathrm{S}_{490}$ (a:30 h:10mm, D: $15 \mathrm{~mm}), \mathrm{S} 3_{490}\left(\mathrm{a}: 30^{\circ}, \mathrm{h}: 20 \mathrm{~mm}, \mathrm{D}: 15 \mathrm{~mm}\right), \mathrm{S5}_{490}\left(\mathrm{a}: 30^{\circ}\right.$, h:30mm, D: $15 \mathrm{~mm})$ ve S7 ${ }_{490}\left(\mathrm{a}: 30^{\circ}, \mathrm{h}: 40 \mathrm{~mm}, \mathrm{D}: 15 \mathrm{~mm}\right)$ nolu numunelerde ' $h$ ' bindirme mesafesinin çekme kuvvetine etkisi 


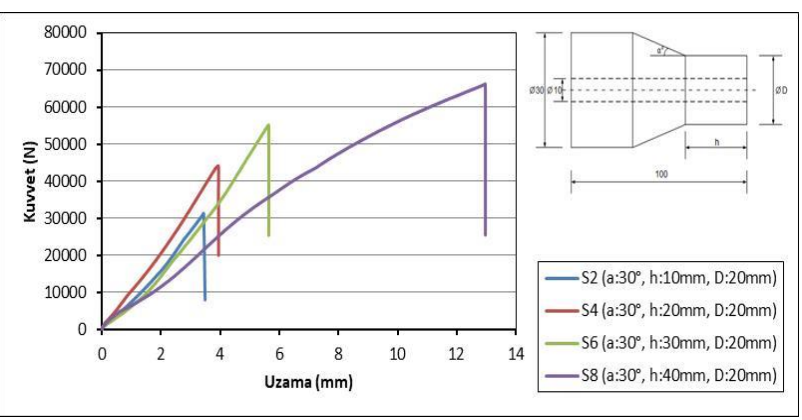

Şekil 8. DP490 yapıştırıcı kullanarak birleştirilen $\mathrm{S} 2_{490}\left(\mathrm{a}: 30^{\circ}, \mathrm{h}: 10 \mathrm{~mm}\right.$, D:20mm), S4 ${ }_{490}\left(\mathrm{a}: 30^{\circ}, \mathrm{h}: 20 \mathrm{~mm}, \mathrm{D}: 20 \mathrm{~mm}\right), \mathrm{S6}_{490}\left(\mathrm{a}: 30^{\circ}, \mathrm{h}: 30 \mathrm{~mm}\right.$, D:20mm) ve $S 8_{490}\left(a: 30^{\circ}\right.$, h:40mm, D:20mm) nolu numunelerde ' $h$ ' bindirme mesafesinin çekme kuvvetine etkisi
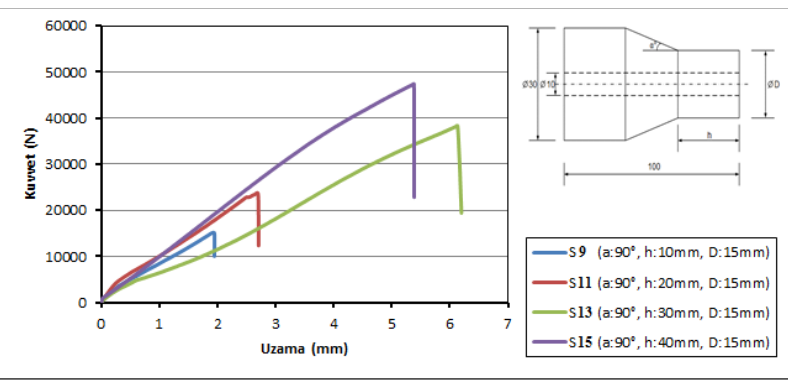

Şekil 9. DP490 yapıștırıcı kullanarak birleștirilen $\mathrm{S} 9_{490}\left(\mathrm{a}: 90^{\circ}, \mathrm{h}: 10 \mathrm{~mm}\right.$, D: $15 \mathrm{~mm}), \mathrm{S}_{11}{ }_{490}\left(\mathrm{a}: 90^{\circ}, \mathrm{h}: 20 \mathrm{~mm}, \mathrm{D}: 15 \mathrm{~mm}\right), \mathrm{S} 13_{490}\left(\mathrm{a}: 90^{\circ}, \mathrm{h}: 30 \mathrm{~mm}\right.$, $\mathrm{D}: 15 \mathrm{~mm})$ ve $\mathrm{S} 15_{490}\left(\mathrm{a}: 90^{\circ}, \mathrm{h}: 40 \mathrm{~mm}, \mathrm{D}: 15 \mathrm{~mm}\right)$ nolu numunelerde ' $h$ ' bindirme mesafesinin çekme kuvvetine etkisi

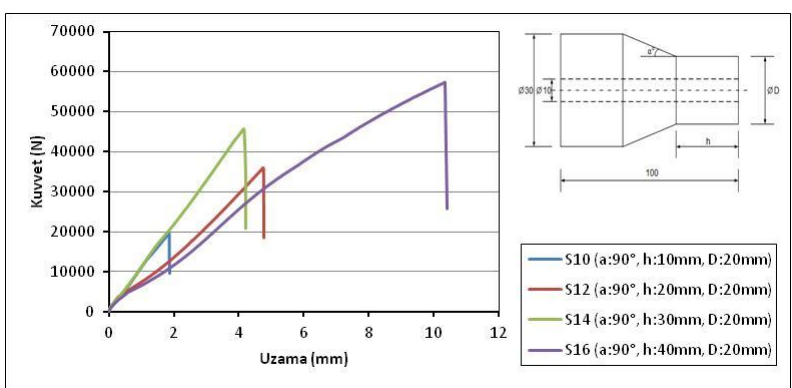

Şekil 10. DP490 yapıştırıcı kullanarak birleştirilen $\mathrm{S}_{10}{ }_{490}$ (a:90', h:10mm, D:20mm), S12 490 (a:90 ${ }^{\circ}$ h:20mm, D:20mm), S14 490 (a: $90^{\circ}$, $\mathrm{h}: 30 \mathrm{~mm}, \mathrm{D}: 20 \mathrm{~mm})$ ve $\mathrm{S} 16_{490}\left(\mathrm{a}: 90^{\circ}\right.$, h:40mm, D:20mm) nolu numunelerde ' $h$ ' bindirme mesafesinin çekme kuvvetine etkisi

Çekme kuvvet değerleri incelendiği, maksimum ve minimum çekme kuvveti değerleri $\mathrm{S}_{490}\left(\mathrm{a}: 30^{\circ}, \mathrm{h}: 40 \mathrm{~mm}\right.$, $\mathrm{D}: 20 \mathrm{~mm})$ ve $\mathrm{S} 9_{490}\left(\mathrm{a}: 90^{\circ}, \mathrm{h}: 10 \mathrm{~mm}, \mathrm{D}: 15 \mathrm{~mm}\right)$ numunelerin de sirasiyla $66183,59 \mathrm{~N}$ ve $15054,69 \mathrm{~N}$ olarak elde edilmiştir. $\mathrm{Bu}$ durumun $\mathrm{h}$ bindirme mesafesinin artmasına paralel olarak yapışma yüzey alanın artmasına bağlı olduğu düşünülmektedir.

\subsection{DP410 ile Birleştirilen Numunelerde 'a' Bindirme Açısının Çekme Kuvvetine Etkisinin İncelenmesi}

DP 410 kullanılarak birleştirilen halka kesitli çubuklarda parametrelerden a açısının etkisi incelenmiştir. İki farklı bindirme açısının kıyaslandığında; DP410 yapıştırıcısı ile iki farklı bindirme açısı $\left(30^{\circ}, 90^{\circ}\right)$ kullanılarak halka kesitli çubuklar birleştirilmiştir. Yapılan birleştirmelerde a bindirme açısının çekme yükü altındaki davranışları incelenmiştir. Numunelerin çekme kuvvetleri altındaki davranışları incelendiğinde a bindirme açısı artıkça çekme yükünün azaldığı görülmüştür. Çekme kuvvet değerleri incelendiği, maksimum ve minimum çekme kuvveti değerleri $\mathrm{S} 8_{410}$ (a:30 $\left.{ }^{\circ} \mathrm{h}: 40 \mathrm{~mm}, \mathrm{D}: 20 \mathrm{~mm}\right)$ ve $\mathrm{S} 9410$ (a: $90^{\circ}, \mathrm{h}: 10 \mathrm{~mm}, \mathrm{D}: 15$ $\mathrm{mm}$ ) numunelerin de sirasıly $104226.6 \mathrm{~N}$ ve $35328,13 \mathrm{~N}$ olarak elde edilmiştir. Genel olarak a bindirme açısının artmasına bağlı olarak yapışma yüzey alanın azalmasına ve çekme kuvvetinin azalmasına neden olduğu görülmektedir.

\subsection{DP490 ile Birleştirilen Numunelerde ' $a$ ' Bindirme Açısının Çekme Kuvvetine Etkisinin İncelenmesi}

DP490 kullanılarak birleştirilen halka kesitli çubuklarda parametrelerden a açısının etkisi incelendiğinde; DP490 yapıştırıcısı ile iki farklı bindirme $\operatorname{açısı~}\left(30^{\circ}\right.$ ve $\left.90^{\circ}\right)$ kullanılarak halka kesitli çubuklar birleştirilmiştir. Yapılan birleştirmelerde a bindirme açısının çekme yükü altındaki davranışları incelenmiştir. Numunelerin çekme kuvvetleri altındaki davranışları incelendiğinde a bindirme açısı artıkça çekme yükünün azaldığ1 görülmüştür. Çekme kuvvet değerleri incelendiği, maksimum ve minimum çekme kuvveti değerleri $\mathrm{S} 8_{490}\left(\mathrm{a}: 30^{\circ} \mathrm{h}: 40 \mathrm{~mm}, \mathrm{D}: 20 \mathrm{~mm}\right)$ ve $\mathrm{S} 9_{490}\left(\mathrm{a}: 90^{\circ}\right.$, h:10mm, D:15 mm) numunelerin de sirasiyla $66183,59 \mathrm{~N}$ ve 15054,69 N olarak elde edilmiştir. Genel olarak a bindirme açısının artmasına bağlı olarak yapışma yüzey alanın azalmasına ve çekme kuvvetinin azalmasına neden olduğu düşünülmektedir.

\subsection{DP410 ile Birleştirilen Numunelerde ' $h$ ' Bindirme Mesafesinin Burulma Açısına Etkisinin İncelenmesi}

JiNAN NDW-200 marka ve maksimum çalışma torku 170 N.m olan burulma cihazında yapılan burulma deneylerinde numuneler deneyler sonucunda hasara uğramamıştır. Bunun için burulma torkunu 70 N.m seçerek bu torka denk gelen burulma açılarını numuneler arasında değerlendirilmiştir. DP410 kullanılarak birleștirilen halka kesitli çubuklarda $\mathrm{h}$ bindirme mesafesinin burulma açısına etkisi incelenmiştir. Dört farklı bindirme mesafesinin $(10 \mathrm{~mm}, 20 \mathrm{~mm}, 30 \mathrm{~mm}$, $40 \mathrm{~mm}$ ) kıyaslanmasıyla oluşturulan grafikler Şekil 11, 12, 13 ve 14 'te gösterilmiştir.

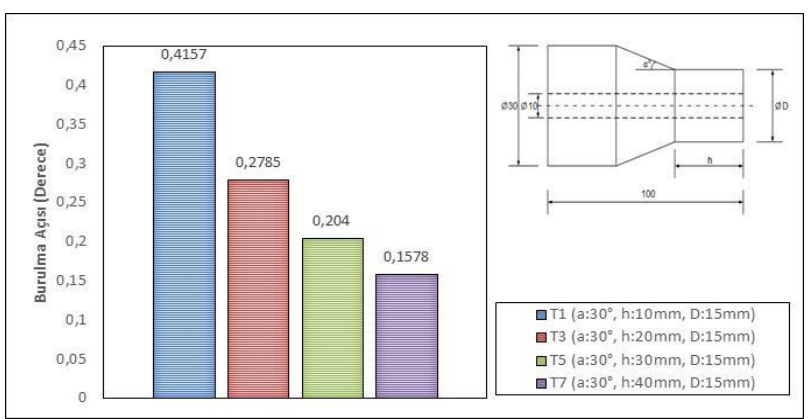

Sekil 11. DP410 yapıștırıcı kullanarak birlestirilen $\mathrm{T} 1_{410}\left(\mathrm{a}: 30^{\circ}\right.$ h:10mm, D:15mm), T3 ${ }_{410}\left(\mathrm{a}: 30^{\circ}, \mathrm{h}: 20 \mathrm{~mm}, \mathrm{D}: 15 \mathrm{~mm}\right), \mathrm{T} 5_{410}\left(\mathrm{a}: 30^{\circ}\right.$, $\mathrm{h}: 30 \mathrm{~mm}, \mathrm{D}: 15 \mathrm{~mm})$ ve $\mathrm{T}_{410}\left(\mathrm{a}: 30^{\circ}, \mathrm{h}: 40 \mathrm{~mm}, \mathrm{D}: 15 \mathrm{~mm}\right)$ nolu numunelerde ' $h$ ' bindirme mesafesinin burulma açısına etkisi

DP410 yapıştırıcısı kullanılarak dört farklı (10mm, 20mm, 30mm, 40mm) h bindirme mesafelerinde halka kesitli çubukların birleştirilmesi yapılmıştır. Yapılan birleştirmelerde $\mathrm{h}$ bindirme mesafesinin burulma açısına 
etkisini incelemek için DP410 ile birleştirilmiş numuneler burulmaya maruz bırakılmıştır.

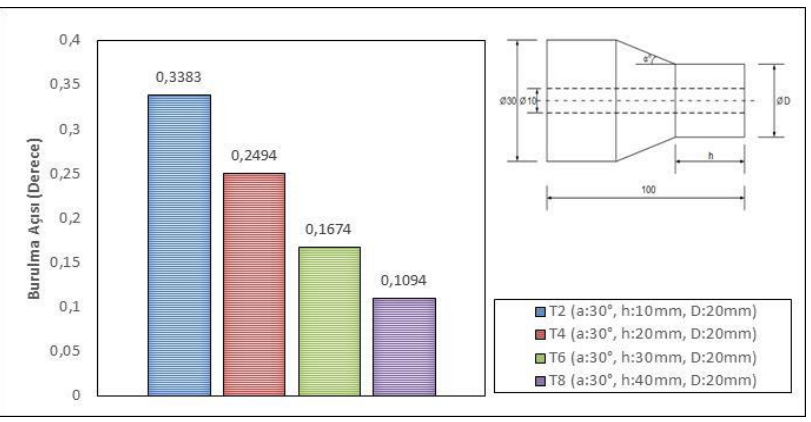

Şekil 12. DP410 yapıștırıcı kullanarak birleștirilen $\mathrm{T} 2{ }_{410}\left(\mathrm{a}: 30^{\circ}\right.$,

h:10mm, D:20mm), T4 $410\left(\mathrm{a}: 30^{\circ}, \mathrm{h}: 20 \mathrm{~mm}, \mathrm{D}: 20 \mathrm{~mm}\right), \mathrm{T}_{410}\left(\mathrm{a}: 30^{\circ}\right.$, $\mathrm{h}: 30 \mathrm{~mm}, \mathrm{D}: 20 \mathrm{~mm})$ ve $\mathrm{T}_{410}\left(\mathrm{a}: 30^{\circ}, \mathrm{h}: 40 \mathrm{~mm}, \mathrm{D}: 20 \mathrm{~mm}\right)$ nolu numunelerde ' $h$ ' bindirme mesafesinin burulma açısına etkisi

Numunelerin burulma altındaki davranışları incelendiğinde genel olarak $\mathrm{h}$ bindirme mesafesi artıkça burulma açısının azaldığı görülmüştür. Burulma açısı değerleri incelendiğinde, maksimum ve minimum burulma açıları $\mathrm{T} 9_{410}$ ve $\mathrm{T} 8_{410}$ nolu numuneler de sirasıyla $0,8334^{\circ}$ ve $0,1094^{\circ}$ olarak elde edilmiştir. Bu durumun $\mathrm{h}$ bindirme mesafesinin artmasına paralel olarak yapışma yüzey alanın artmasına bunun bağlantı mukavemetini arttırması ve burulma açısının azalmasına sebep olduğu görülmüştür.

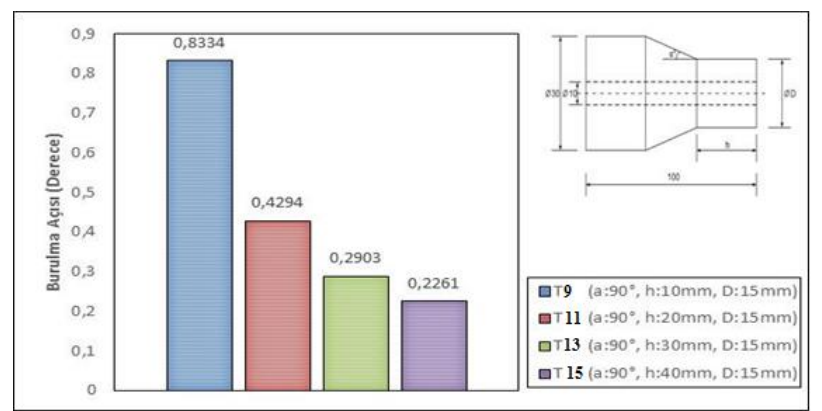

Şekil 13. DP410 yapıştırıcı kullanarak birleştirilen $\mathrm{T} 9_{410}\left(\mathrm{a}: 90^{\circ}\right.$,

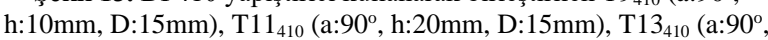
h:30mm, D: $15 \mathrm{~mm}$ ) ve T15 ${ }_{410}$ (a: $90^{\circ}$, h:40mm, D: $15 \mathrm{~mm}$ ) nolu numunelerde ' $\mathrm{h}$ ' bindirme mesafesinin burulma açısına etkisi

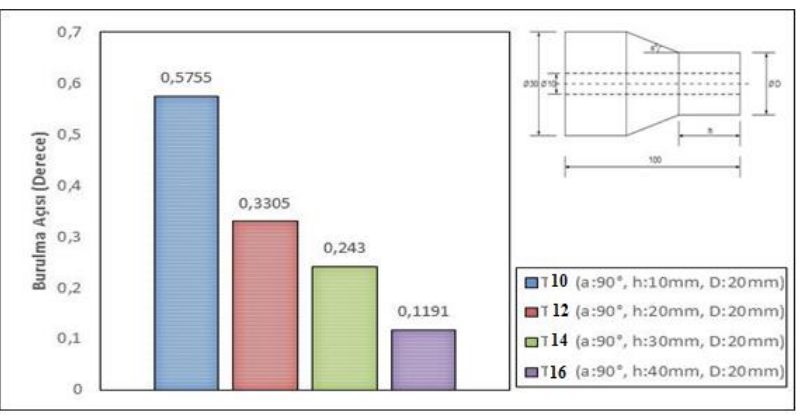

Şekil 14. DP410 yapıștırıcı kullanarak birleștirilen $\mathrm{T} 10_{410}\left(\mathrm{a}: 90^{\circ}\right.$, h:10mm, D:20mm), T12 ${ }_{410}\left(\mathrm{a}: 90^{\circ}, \mathrm{h}: 20 \mathrm{~mm}, \mathrm{D}: 20 \mathrm{~mm}\right), \mathrm{T} 14_{410}\left(\mathrm{a}: 90^{\circ}\right.$, h:30mm, D:20mm) ve T16 410 (a: $90^{\circ}$, h:40mm, D:20mm) nolu numunelerde ' $\mathrm{h}$ ' bindirme mesafesinin burulma açısına etkisi

\subsection{DP490 ile Birleştirilen Numunelerde ' $h$ ' Bindirme Mesafesinin Burulma Açısına Etkisinin İncelenmesi}

DP490 kullanılarak birleştirilen halka kesitli çubuklarda h bindirme mesafesinin burulma açısına etkisi incelenmiştir. Dört farklı bindirme mesafesinin $(10 \mathrm{~mm}$, 20mm, 30mm, 40mm) kıyaslanmasıyla oluşturulan grafikler Şekil 15, 16, 17 ve 18'de verilmiştir.

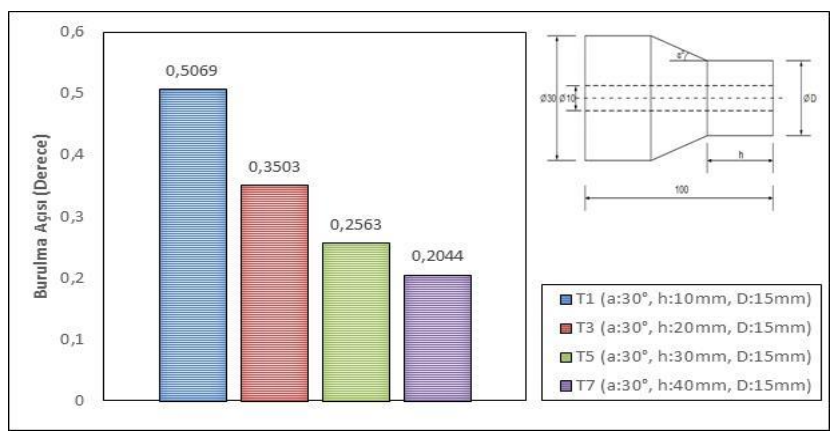

Şekil 15. DP490 yapıştırıcı kullanarak birleştirilen $\mathrm{T} 1_{490}$ (a:30, h:10mm, D:15mm), T3 ${ }_{490}\left(\mathrm{a}: 30^{\circ}, \mathrm{h}: 20 \mathrm{~mm}, \mathrm{D}: 15 \mathrm{~mm}\right), \mathrm{T}_{490}\left(\mathrm{a}: 30^{\circ}\right.$, h:30mm, D: $15 \mathrm{~mm})$ ve T7 490 (a:30 , h:40mm, D: $15 \mathrm{~mm}$ ) nolu numunelerde ' $h$ ' bindirme mesafesinin burulma açısına etkisi

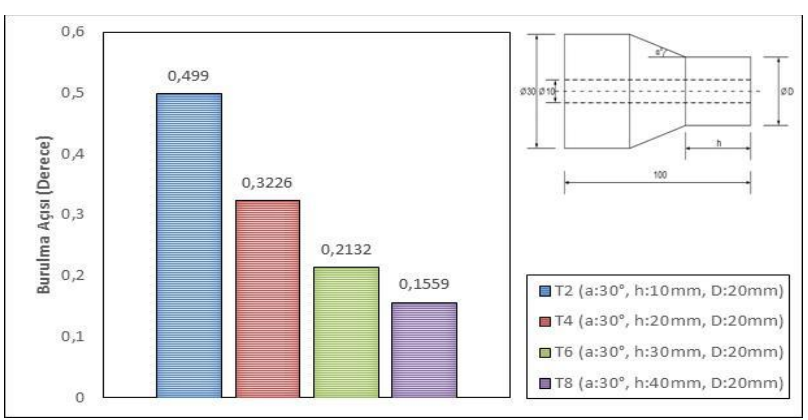

Şekil 16. DP490 yapıştırıcı kullanarak birleştirilen $\mathrm{T} 2{ }_{490}$ (a: $30^{\circ}$, h:10mm, D:20mm), T4 490 (a:30 , h:20mm, D:20mm), T6 490 (a:30, h:30mm, D:20mm) ve T8 ${ }_{490}\left(\mathrm{a}: 30^{\circ}, \mathrm{h}: 40 \mathrm{~mm}, \mathrm{D}: 20 \mathrm{~mm}\right)$ nolu numunelerde ' $h$ ' bindirme mesafesinin burulma açısına etkisi

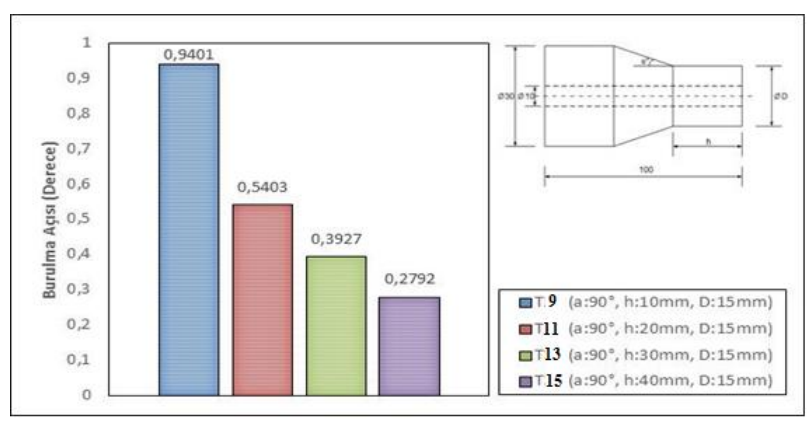

Sekil 17. DP490 yapıștırıcı kullanarak birleștirilen $\mathrm{T} 9_{490}$ (a:90,

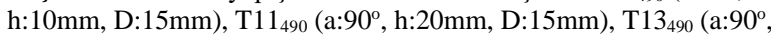
$\mathrm{h}: 30 \mathrm{~mm}, \mathrm{D}: 15 \mathrm{~mm})$ ve T15 ${ }_{490}\left(\mathrm{a}: 90^{\circ}, \mathrm{h}: 40 \mathrm{~mm}, \mathrm{D}: 15 \mathrm{~mm}\right)$ nolu numunelerde ' $h$ ' bindirme mesafesinin burulma açısına etkisi

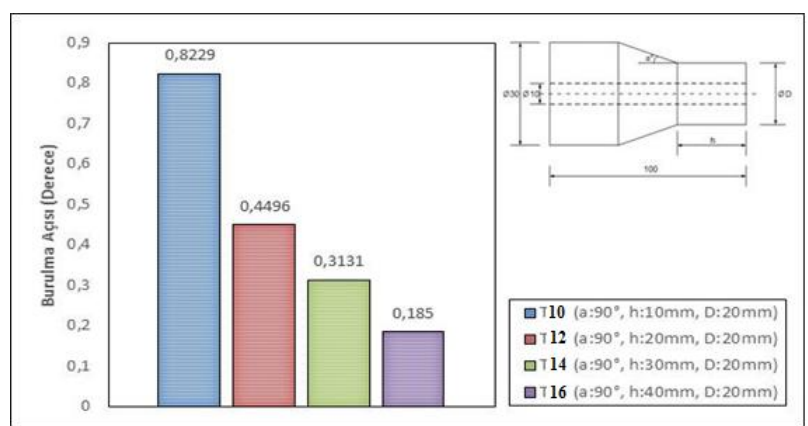

Şekil 18. DP490 yapıştırıc kullanarak birleştirilen $\mathrm{T} 10_{490}$ (a: $90^{\circ}$,

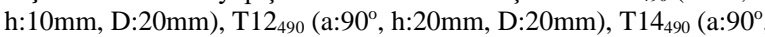
h:30mm, D:20mm) ve T16 490 (a: $\left.90^{\circ}, \mathrm{h}: 40 \mathrm{~mm}, \mathrm{D}: 20 \mathrm{~mm}\right)$ nolu numunelerde ' $h$ ' bindirme mesafesinin burulma açısına etkisi 
DP490 yapıştırıcısı kullanılarak dört farklı (10mm, 20mm, 30mm, 40mm) h bindirme mesafelerinde halka kesitli çubukların birleştirilmesi yapılmıştır. Yapılan birleştirmelerde $\mathrm{h}$ bindirme mesafesinin burulma açısına etkisini incelemek için DP490 ile birleştirilmiş numuneler burulmaya maruz bırakılmıştır. Numunelerin burulma altındaki davranışları incelendiğinde genel olarak $h$ bindirme mesafesi artıkça burulma açısının azaldığı görülmüştür. Burulma açısı değerleri incelendiğinde, maksimum ve minimum burulma açıları $\mathrm{T} 9_{490}$ ve $\mathrm{T} 8_{490}$ nolu numuneler de sirasiyla $0,9401^{\circ}$ ve $0,1559^{\circ}$ olarak elde edilmiştir. $\mathrm{Bu}$ durumda $\mathrm{h}$ bindirme mesafesinin artışıyla burulma açılarında azalma meydana gelmiştir. Bunun sebebi mesafe artışıyla yüzey alanında artış olmaktadır ve bu durumun bağlantı mukavemetini yükseltirken burulma açısında azalmaya sebep olmuştur.

\section{Sonuçlar}

$\mathrm{Bu}$ çalışmada; halka kesitli çubukların birleştirilmesinde çevresel yapışma yüzeyinin bağlantı mukavemetine etkisini incelemek için iki farklı özelliğe sahip yapıştırıcı (DP410 ve DP490) dört farklı bindirme mesafesi $(10,20,30$ ve $40 \mathrm{~mm})$, iki farklı bindirme açısı $\left(30^{\circ}\right.$ ve $\left.90^{\circ}\right)$ ve farklı bindirme iç açısına sahip parçalar farklı parametrelerde birleştirilip çekme ve burulma deneylerine tabi tutulmuştur. Deneysel çalışma ile elde edilen sonuçlar aşağıda verilmiştir.

1. Birleştirmelerin çekme kuvvetleri altındaki davranışları incelendiğinde genel olarak h bindirme mesafesi artıkça çekme yükünün arttığı ve a açısı arttıkça çekme yükünün azaldığı görülmüştür.

2. Çekme kuvvet değerleri incelendiği, maksimum ve minimum çekme kuvveti değerleri $\mathrm{S} 8410$ ve $\mathrm{S} 9_{410}$ nolu numuneler de sirasiyla $104226,6 \mathrm{~N}$ ve 35328,13 $\mathrm{N}$ olarak elde edilmiştir.

3. DP410 yapıştırıcıyla yapıştırılan numunelerin burulma deneyleri de yapılmıştır. Burulma deneyleri incelendiğinde ise maksimum burulma açısı T9 410 numunesinde $0,8334^{\circ}$ ve minimum burulma açısı $\mathrm{T}_{410}$ num unede $0,1094^{\circ}$ derece olarak gözlemlenmiştir. $\mathrm{Bu}$ durumun $\mathrm{h}$ bindirme mesafesinin artmasına paralel olarak yapışma yüzey alanın artmasına, a bindirme çapının artışılla yüzey alanı azalmasına bağlı olarak değişim göstermişitr.

4. Yapılan birleştirmelerde DP490 ile birleştirilmiş numunelerin çekme deneyleri yapılmıştır. Belirlenen parametreler ışığında deneyleri yapılan numunelerin çekme davranışları incelendiğinde $h$ bindirme mesafesi artışıyla çekme kuvvetleri artarken, a bindirme çapının artışıla çekme kuvvetinde azalma gözlemlenmiştir. Çekme deneyleri neticesinde maksimum çekme kuvveti $\mathrm{S} 8_{490}$ numunesinde $66183,59 \mathrm{~N}$ ve minimum çekme kuvveti $\mathrm{S} 9490$ numunede 15054,69 $\mathrm{N}$ elde edilmiştir.

5. DP490 yapıştırıcısıyla yapıştırılan numunelerin burulma deneyleri neticesinde elde edilen burulma açıları incelenmiştir. Maksimum ve minimum burulma açıları sırasıyla T25490 numunesinde $0,9401^{\circ}$ ve $\mathrm{T}_{490}$ numunesinde $0,1559^{\circ}$ gözlemlenmiştir. Elde edilen veriler değerlendirildiğinde numunelerde yüzey alanlarında artış bağlantı mukavemetine olumlu yönde etki gösterdiği düşünülmektedir.

6. İki farklı yapıştırıcıyla birleştirilen halka kesitli çubukların çekme deneyleri neticesinde kullanılan yapıştırıcıların bağlantı mukavemetine etkisi incelendiğinde; DP410 yapıştırıcısıyla yapıştırılan numunelerin DP490 yapıştırıcısıyla yapıştırılan numunelere göre çekme kuvveti değerleri daha yüksek çıkmıştır. Burulma davranışları açısından da DP410 yapıştırıcısıyla yapıştırılan numunelerin DP490 yapıştırıcısıyla yapıştırılan numunelere göre daha iyi davranış göstermiştir.

\section{Teşekkür}

Bu çalışma Bingöl Üniversitesi Bilimsel Araştırmalar Birimi Tarafindan BAP-MMF.2018.00.003 nolu proje kapsamından desteklenmiştir. Katkılarından dolayı Bingöl Üniversitesi BAP birimine teşekkür ederiz.

\section{Kaynaklar}

[1] Solmaz, M.Y., Turgut, A., An Experimental and Numerical Study on the Effects of Taper Angles and Overlap Length on the Failure and Stress Distribution of AdhesivelyBonded Single-Lap Joints, The 1st International Symposium on Computing in Science \& Engineering (ISCSE), June, 3-5, p. 866-874, Kusadasi, Aydin, 2010.

[2] Solmaz M.Y., Yapıştırıcı İle Birleştirilmiş Bağlantıların Mekanik Analiz ve Tasarımları, Doktora Tezi, Fırat Üniversitesi Fen Bilimleri Enstitüsü, Elazı ̆̆, 2008.

[3] Taş B., Yapıştırıcı İle Birleştirilmiş Konik Geçmeli Bağlantıların Burulma Momenti Altındaki Performansları, Yüksek Lisans Tezi, Fırat Üniversitesi Fen Bilimleri Enstitüsü, Elazı ̆ 2016.

[4] Hur, S.H., Son, H.J., Kweon, J. H., Choi, J.H., Postbuckling of composite cylinders under external hydrostatic pressure, Composite Structures, 2008.

[5] Tafresi, A., Bailey C. G., Instability of imperfect composite cylindrical shells under combined loading, Composite structures 80, 49-64, 2007.

[6] Yang, C., Huang, H., Guan, Z., Stress Model of Composite Pipe Joints under Bending, Journal of Composite Materials, 36, 1331, 2002

[7] Gül A., Yapıştırma bağlantılı kompozit boruların burkulma analizi, Yüksek Lisans Tezi, Atatürk Üniversitesi Fen Bilimleri Enstitüsü, Erzurum, 2013.

[8] Aimmanee S., Hongpimolmas P., Stress analysis of adhesive-bonded tubular-coupler joints with optimum variable-stiffness composite adherend under torsion, composite structures 164,76-89, 2017.

[9] Oh J.H., torque capacity of tubular adhesive joints with different composite adherends, materials letters 62, 1234 1237,2008

[10] Jeroen Van, W., Jan De, P., Patrick De, B., Wim De, W., Magd A.W., Guido De, R., Experimental determination of the fatigue life of modified threaded pipe couplings, Procedia Engineering 2,1849-1858, 2010.

[11] Vaziri A., Nayeb-Hashemi H., Dynamic response of tubular joints with an annular void subjected to a harmonic axial load, International Journal of Adhesion and Adhesives 22, 367-373, 2002. 
[12] Das R.R., Baishya N., Failure Analysis of Bonded Composite Pipe joints subjected to internal Pressure and Axial loading, Procedia Engineering, 1047-1054, 2016.

[13] Li, H., Zhang, X., Qi, D., Cai, X., Ding, N., Wei, B., Qi, G., Failure analysis of the adhesive metal joint bonded on anticorrosion plastic alloy composite pipe, Engineering Failure Analysis 47,49-45, 2015.

[14] Rohem, N.R.F., Pacheco, L.J., Budhe, S., Banea, M.D., Sampaio, E.M., de Barros, S., Development and qualification of a new polymeric matrix laminated composite for pipe repair, Composite Structures 152, 737 $745,2016$.

[15] Liu, J., Qin, M., Zhao, Q., Chen., Liu, P., Gao, J., Fatigue performances of the cracked aluminum-alloy pipe repaired with a shaped CFRP patch, Thin-Walled Structures111, 155-164, 2017. 